\title{
ADMINISTRAÇÃO DA INFORMAÇÃO ENERGÉTICA
}

\author{
Administration of energy information
}

\author{
Fabricio Quadros Borges ${ }^{1}$ \\ Fabrini Quadros Borges ${ }^{2}$ \\ Sara de Souza Ribeiro ${ }^{3}$
}

\begin{abstract}
RESUMO: Este artigo objetiva introduzir uma visão abrangente e integrada da Administração direcionada para a informação energética, por meio de uma contribuição a formulação de indicadores de sustentabilidade energética. Esta contribuição possui o intuito de orientar estratégias voltadas para políticas de investimento no setor elétrico paraense. A metodologia utilizada baseou-se inicialmente em um levantamento bibliográfico sobre os modelos de indicadores de sustentabilidade de energia elétrica a luz do desenvolvimento sustentável. Em seguida, reuniu elementos para a elaboração de uma proposta de indicadores de sustentabilidade energética baseada em correlações lineares. Os indicadores foram estruturados a partir dos setores de atividade: agropecuário, industrial, comercial e residencial, de modo a considerar as dimensões de análise: econômica, social, ambiental e política, em cada um destes setores. A investigação constatou que a observância de elementos locacionais identificados setorialmente pelas correlações lineares reúne maiores condições de percepção das particularidades econômicas, sociais e ambientais do Estado paraense e permite orientar a tomada de decisão no setor elétrico paraense.
\end{abstract}

Palavras-chaves: Informação energética. Indicadores. Desenvolvimento sustentável. Energia 44 elétrica. Processo decisório.

ABSTRACT: This article aims to introduce a comprehensive and integrated vision of the Administration directed to energy information from a contribution to the formulation of energy sustainability indicators. This contribution aims to guide strategies to policies investment in the Pará electric sector. The methodology used was initially based on a bibliographic survey on the models of electricity sustainability indicators in the light of sustainable development. Then, it gathered elements for the elaboration of a proposal for energy sustainability indicators based on linear correlations. The indicators were structured based on the sectors of activity: agricultural, industrial, commercial, and residential, to consider the dimensions of analysis: economic, social, environmental and political, in each of these sectors. The investigation found that the observance of locational elements identified sectorally by linear correlations brings together greater conditions of perception of the economic, social, and environmental particularities of the State of Pará and allows to guide decision making in the Pará electric sector.

Keywords: Energy information. Indicators. Sustainable development. Electricity. Decision-making process.

\footnotetext{
${ }^{1}$ Pós-Doutor em Gestão de Tecnologia pelo IPEN/USP- Instituto Federal do Pará - IFPA/ Universidade da Amazônia - UNAMA. E-mail:posdoctorborges@gmail.com.

2 Doutor em Administração pela UNAMA/ Universidade do Estado do Pará - UEPA. Email:doctorborges@bol.com.br.

3 Doutoranda em Administração pela UNAMA-Universidade da Amazônia. E-mail: sarasr@gmail.com.
} 


\section{INTRODUÇÃO}

A informação energética é construída e gerenciada através de um conjunto de organizações públicas e privadas que procuram promover a utilização estratégica de diferentes fontes de energia a partir de recursos energéticos, econômicos e tecnológicos disponíveis. Neste sentido, estas informações compreendem um sistema aberto que estabelece relações entre seus subsistemas: elétrico, carvão, petróleo, gás e outros. O uso da informação energética sempre assumiu papel importante na geopolítica mundial e nos padrões competitivos utilizados na exploração de recursos projetados nas matrizes energéticas nacionais e sempre promoveram reflexos nas relações de poder. A compreensão da dinâmica das mudanças globais representa a possibilidade de reunir condições de tratar a informação energética como instrumento estratégico. Estudos relacionados a indicadores de sustentabilidade energética, uso estratégico de fontes alternativas para este insumo, o papel institucional no setor elétrico brasileiro e impactos socioambientais do uso de fontes energéticas compõem este panorama de investigação. Esta contribuição possui o intuito de discorrer em direção a como orientar estratégias voltadas para políticas de investimento no setor elétrico paraense a partir de indicadores de sustentabilidade energética. A seguir, apresenta-se uma contribuição pertinente ao ambiente dos indicadores de sustentabilidade energética voltada ao estado do Pará, a todos os interessados em participar dos debates de maneira a esperar que este conteúdo possa agregar à formulação e ao desenvolvimento de estudos pertinentes a esta temática tão relevante.

\section{O DESENVOLVIMENTO SUSTENTÁVEL E OS INDICADORES DE SUSTENTABILIDADE ENERGÉTICA}

O debate conceitual sobre o desenvolvimento sustentável é cercado de contradições. Conforme Kitamura (1994), este desenvolvimento vincula-se a uma ética que incorpora tanto os valores ecológicos quanto espirituais. O problema reside no fato de que os interesses econômicos não são submissos às noções de ética. Seu conceito supõe ainda uma nova ordem internacional, que tem como produto uma ampla redistribuição do poder (KITAMURA, 1994). A ideia desta nova ordem de desenvolvimento, entretanto, ignora as correlações de forças que são atuantes no mercado mundial, e os interesses das nações industrializadas em manter a posição de vantagem no panorama internacional (SPANGENBERG, 2000).

Tomando como base esta percepção contraditória, a discussão sobre esta temática está intimamente relacionada ao debate a respeito de metodologias para a medição do nível do desenvolvimento de sociedades e da sustentabilidade de seus sistemas de produção (REIS; 
FADIGAS; CARVALHO, 2012). Segundo Bruyn e Drunden (1999), os parâmetros forneceriam informações sobre um determinado fenômeno que é importante para o desenvolvimento e seriam demonstrados através de indicadores.

$\mathrm{O}$ ambiente que envolve o setor energético caracteriza-se como um segmento estratégico e impulsor ao processo de desenvolvimento, uma vez que possibilita a promoção de várias necessidades básicas da população. Destarte, busca-se identificar no cenário do setor elétrico, elementos que possam expressar relações de sustentabilidade envolvendo os aspectos: econômico, social, ambiental e político. O capítulo 9 da Agenda 2i ressalta que a energia é essencial para o desenvolvimento socioeconômico e para uma melhor qualidade de vida. Segundo Suárez (1995) a energia possui uma missão importante em relação ao Índice de Desenvolvimento Humano (IDH).

$\mathrm{Na}$ tentativa de realizar uma discussão mais específica a respeito de indicadores de sustentabilidade energética, Bermann (2003) considera esses indicadores como ferramentas necessárias para operacionalização dos propósitos na perspectiva do desenvolvimento sustentável e fundamentais referências no processo decisório. Assim, o autor elabora indicadores que tratam as dimensões: energia e equidade, energia e meio ambiente, energia e emprego, energia e eficiência, e energia e democracia. No indicador energético de equidade as variáveis apresentadas por Bermann (2003) são: participação da dendroenergia no consumo energético do setor residencial; taxa de eletrificação dos domicílios; posse de equipamentos eletrodomésticos básicos; carência energética (para a definição de uma cesta básica energética); forma de energia elétrica utilizada; e gastos energéticos em função da renda familiar (esta variável possui o propósito de avaliar o nível de comprometimento da renda familiar com gastos no atendimento das demandas energéticas). Em relação ao indicador energético de meio ambiente as variáveis são: emissões de $\mathrm{CO}_{2}$ por fonte energética (importante não apenas pela relevância da questão em si, mas pelo problema do aquecimento global decorrente das emissões de gases de efeito estufa) e a participação das fontes renováveis na oferta energética. No indicador energético de emprego o autor demonstra o potencial de geração de empregos através dos setores de atividade econômica (BORGES, 2009). No que se refere ao indicador energético de eficiência, é abordado o rendimento energético médio. E no indicador energético da democracia, o autor trata da publicização, que compreende o acesso da população às informações pertinentes ao setor elétrico através dos meios de comunicação, enquanto instrumentos políticos (BERMANN, 2003). Observa-se através do Quadro I, a seguir, os indicadores de sustentabilidade energética elaborados por Célio Bermann:

Quadro I: Modelo de indicadores de sustentabilidade energética elaborados por Célio Bermann 


\begin{tabular}{|c|c|}
\hline DIMENSÃO & INDICADORES \\
\hline \multirow{4}{*}{ Energia e equidade } & $\begin{array}{l}\text { - Participação da dendroenergia no consumo energético } \\
\text { do setor residencial; }\end{array}$ \\
\hline & $\begin{array}{l}\text { - Taxa de eletrificação dos domicílios } \\
\text { - Posse de equipamentos eletrodomésticos básicos } \\
\text { carência energética }\end{array}$ \\
\hline & - $\quad$ Forma de energia elétrica utilizada; \\
\hline & Gastos energéticos em função da renda familiar. \\
\hline \multirow{2}{*}{$\begin{array}{l}\text { Energia e meio } \\
\text { ambiente }\end{array}$} & Emissões de $\mathrm{CO}_{2}$ por fonte energética \\
\hline & - $\quad$ Participação das fontes renováveis na oferta energética. \\
\hline Energia e emprego & $\begin{array}{l}\text { Potencial de geração de empregos através dos setores de } \\
\text { atividade econômica. }\end{array}$ \\
\hline Energia e eficiência & Rendimento energético médio \\
\hline Energia e democracia & Publicização \\
\hline
\end{tabular}

Fonte: Elaborado pelo autor (2020) baseada em Bermann (2003).

A Helio International, que trata-se de uma rede não-governamental sediada na França, Paris, e criada em 1997, é formada por um grupo de especialistas na área energética. Em sua análise da sustentabilidade, utiliza-se de um conjunto de oito indicadores, divididos em quatro dimensões: ambiental, que apresenta como indicadores os impactos globais (emissões per capita de carbono no setor energético) e locais (nível de poluentes locais mais significantes relacionados à energia); social, apontando como indicadores os domicílios com acesso à eletricidade (percentual de domicílios com acesso à eletricidade) e os investimentos em energia limpa, como um incentivo à criação de empregos (investimentos em energia renovável e eficiência energética em usos finais, como um percentual do total de investimentos no setor energético). (BORGES, 2009). No tocante à dimensão econômica, a Helio Internacional (2005) propõe indicadores como a exposição a impactos externos (exportação de energia não-renovável como um percentual do valor total de exportação e importação de energia nãorenovável como um percentual da oferta total primária de energia); carga de investimento em energia no setor público (investimento público em energia não-renovável como percentual do PIB); e, por fim a dimensão tecnológica, que trabalha como indicadores a intensidade energética (consumo de energia primária por unidade do PIB) e a participação de fontes renováveis na oferta primária de energia (HELIO INTERNACIONAL, 2005). A seguir, verifica-se através do Quadro 2, os indicadores de sustentabilidade energética elaborados pela Helio Internacional. O grupo de especialistas da Helio Internacional (2005) destaca ainda a necessidade de comparação entre situações anteriores e situações futuras no esforço de avaliar o grau do processo de desenvolvimento socioeconômico, de forma a possibilitar orientações ao processo de tomada de decisão no setor elétrico. 
Quadro 2: Modelo de indicadores de sustentabilidade energética elaborados pela Helio Internacional.

\begin{tabular}{|c|c|}
\hline DIMENSÃO & INDICADORES \\
\hline Ambiental & $\begin{array}{ll}\text { - } & \text { Impactos globais } \\
\text { - } & \text { Impactos locais }\end{array}$ \\
\hline Social & $\begin{array}{l}\text { Domicílios com acesso à eletricidade } \\
\text { - Investimentos em energia limpa, como um } \\
\text { incentivo à criação de empregos. }\end{array}$ \\
\hline Econômica & 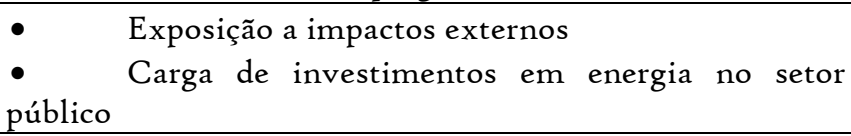 \\
\hline Tecnológica & $\begin{array}{l}\text { - Intensidade energética } \\
\text { - Participação de fontes renováveis na oferta } \\
\text { primária de energia }\end{array}$ \\
\hline
\end{tabular}

Fonte: Elaborado pelo autor (2020) baseada na Helio Internacional (2005).

A Aneel (1999) afirma que os indicadores energéticos são instrumentos: de comunicação entre tomadores de decisão e o grande público; de informaç̃̃es quantitativas sobre a sustentabilidade de sistemas energéticos; de integração do uso e redução de desperdícios. Os indicadores apresentados pela Aneel foram desenvolvidos a partir das diretrizes da Organização Latino-Americana de Energia (Olade) (1996) e dividem-se em aspectos políticos: segurança no abastecimento e desconcentração de poder público; econômicos: equilíbrio no balanço de pagamentos e apropriação de renda e geração de receitas físicas; sociais: geração de empregos e redução de desigualdades regionais; ecológicos: minimização de impactos sobre o meio ambiente físico e biótico e máxima valorização de recursos energéticos renováveis; e tecnológicos: qualidade e confiabilidade adequadas e minimização de riscos de acidentes. (BORGES, 2009). A relação de indicadores da Aneel pode ser verificada através do Quadro 3:

Quadro 3: Modelo de indicadores de sustentabilidade energética elaborados pela Aneel

\begin{tabular}{|c|ll|}
\hline DIMENSÃO & \multicolumn{1}{c|}{ INDICADORES } \\
\hline POLÍTICA & $\bullet$ & Segurança no abastecimento \\
& $\bullet$ & Desconcentração de poder público \\
\hline ECONÔMICA & $\bullet$ & Equilíbrio no balanço de pagamentos \\
\hline SOCIAL & $\bullet$ & Apropriação de renda e geração de receitas físicas \\
\hline \multirow{2}{*}{ ECOLÓGICA } & $\bullet$ & Geração de empregos \\
& $\bullet$ & Redução de desigualdades regionais \\
\hline & $\bullet$ & Minimização de impactos sobre o meio ambiente físico \\
TECNOLÓGICA & $\bullet$ & Máxima valorização de recursos energéticos renováveis \\
\hline
\end{tabular}


Fonte: Elaborado pelo autor (2020) baseada em informações da Aneel (1999).

Em âmbito mais específico, Camargo, Ugaya e Agudelo (2004) desenvolvem estudos a respeito dos indicadores de sustentabilidade energética a partir de um dos componentes do sistema elétrico, a geração de energia. A proposta de Camargo, Ugaya e Agudelo (2004) possui um enfoque voltado a indicadores empresariais ou corporativos aplicáveis ao setor elétrico brasileiro. Estes indicadores podem ser: sociais, econômicos e ambientais (BORGES, 2009).

Os indicadores sociais são: alimentação; encargos sociais; valor pago à previdência privada; assistência médica e social aos empregados; número de acidentes de trabalho; investimento em educação dos empregados; número de doenças ocupacionais; investimentos em projetos culturais para os empregados; capacidade de desenvolvimento profissional; número de mulheres que trabalham na empresa; auxílio creche; participação nos resultados da empresa; transparência e comunicação das informações; número de empregados portadores de deficiência; percentual de cargos de chefia ocupados por mulheres; eficácia das contribuições para a sociedade; ações judiciais relativas a problemas ambientais; empregados treinados ISO I4.004; investimentos em educação para a comunidade; investimentos em projetos sociais; investimentos em pesquisa universitária (CAMARGO; UGAYA; AGUDELO, 2004).

Os indicadores econômicos são: despesas com salários e benefícios; impostos e taxas em geral; investimento em segurança, meio ambiente e saúde; investimento em pesquisa e desenvolvimento; investimento em desenvolvimento comunitário; investimento em tecnologia nacional; e patrocínio de projetos ambientais (BORGES, 2009).

Por fim, os indicadores ambientais são: qualidade do ar; eficiência energética; utilização de recursos naturais; qualidade ambiental; qualidade da água; e responsabilidade ambiental. Observa-se através do Quadro 4, a seguir, os Indicadores de sustentabilidade energética elaborados por Camargo, Ugaya e Agudelo (2004).

Quadro 4: Modelo de indicadores de sustentabilidade energética elaborados por Camargo, Ugaya e Agudelo.

\begin{tabular}{|c|cl|}
\hline DIMENSÃO & & \multicolumn{1}{c|}{ INDICADORES } \\
\hline & $\bullet$ & Alimentação e encargos sociais \\
& $\bullet$ & Valor pago à previdência privada \\
SOCIAL & $\bullet$ & Assistência médica e social aos empregados \\
& $\bullet$ & Número de acidentes de trabalho \\
& $\bullet$ & Investimento em educação dos empregados \\
& $\bullet$ & Número de doenças ocupacionais \\
\hline
\end{tabular}




\begin{tabular}{|c|c|}
\hline & 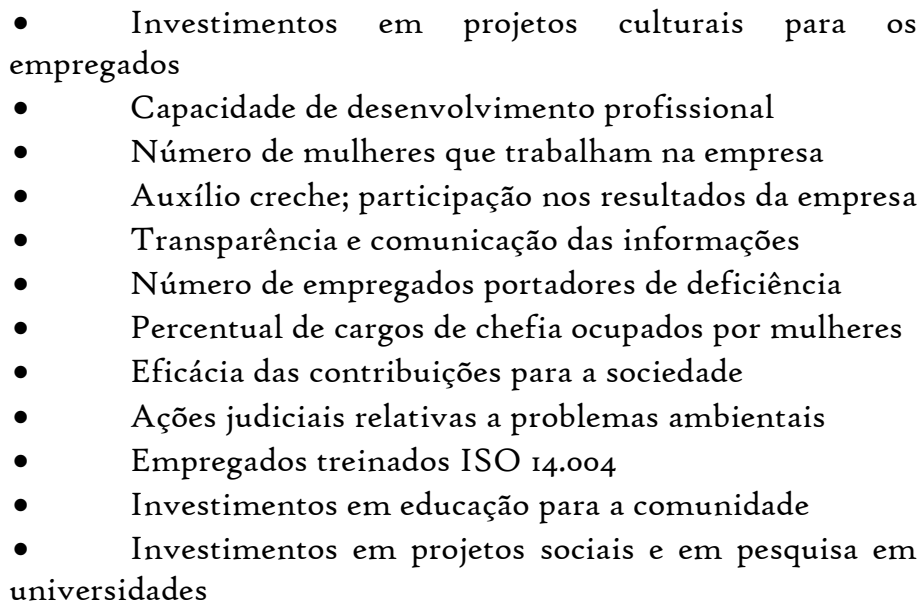 \\
\hline ECONÔMICA & 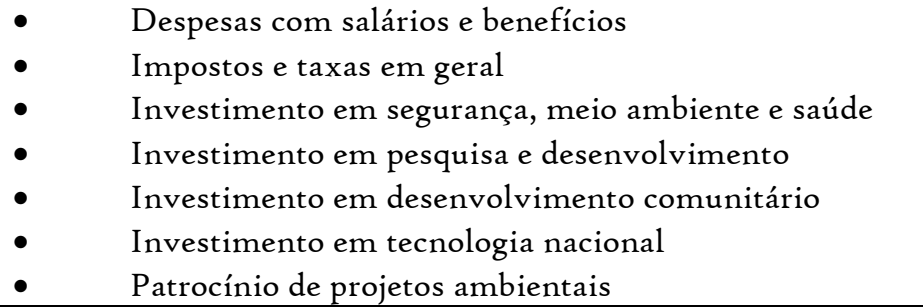 \\
\hline AMBIENTAL & $\begin{array}{ll}\text { - } & \text { Qualidade do ar } \\
\text { - } & \text { Eficiência energética } \\
\text { - } & \text { Utilização de recursos naturais } \\
\text { - } & \text { Qualidade ambiental } \\
\text { - } & \text { Qualidade da água } \\
\text { - } & \text { Responsabilidade ambiental }\end{array}$ \\
\hline
\end{tabular}

Fonte: Elaborado pelo autor (2020) baseada em Camargo, Ugaya e Agudelo (2004).

A totalidade destes indicadores foi obtido a partir da combinação de indicadores das empresas: Hydro Québec (Canadá), Petrobras (Brasil) e Tennessee Valley Autorithy (EUA). Os autores acreditam que o produto desta combinação é perfeitamente aplicável ao setor elétrico brasileiro. Entretanto, em virtude de especificidades do sistema elétrico nacional, fica registrada a necessidade de se continuar os estudos a respeito deste assunto (CAMARGO; UGAYA; AGUDELO, 2004).

Em âmbito global, todas as proposições de construção de indicadores de sustentabilidade energética, aqui discutidas, procuraram utilizar dimensões que atendessem aos propósitos que lhe fundamentaram. Neste sentido, destaca-se que o propósito de analisar o papel do setor elétrico na melhoria concreta da qualidade de vida da população indica a necessidade de se considerar as dimensões: econômica, social, ambiental e política; conforme a estrutura recomendada pela CDS em análises com perspectiva ao desenvolvimento sustentável. 
A dimensão econômica está alicerçada no papel da mercadoria energética no mercado através dos termos de troca que procuram promover um processo de acumulação de capital. Como observa Bermann (2003), o valor da mercadoria energética no mercado determina diretamente a taxa de lucro da atividade produtiva. A dimensão social, por sua vez, é verificada pela identificação de níveis básicos de necessidades, ou seja, é caracterizada pela possibilidade de utilizar o insumo energético em condições mínimas. A dimensão social detém o caráter mais desafiador (REIS; FADIGAS; CARVALHO, 2012).

Já a dimensão ambiental é identificada pelo nível de deterioração que a utilização da energia pode causar ao meio ambiente. A eletricidade é usada em diversos setores como o agropecuário, industrial, comercial e residencial; em cada um deles a energia é transformada de acordo com os propósitos destas atividades, processo chamado de metabolismo energético-material, que no caso das sociedades industrializadas apresenta um intensivo consumo de matéria e energia (FISCHERKOWALSKI et al., 1997; KALTENEGGER, I995; SMIL, I993).

Por fim, a dimensão política é caracterizada pela dinâmica que pauta as relações entre o setor de energia elétrica e a sociedade. O planejamento público e o grau de participação da sociedade neste processo vêm representar o caráter político do insumo energético. Entretanto, o maior desafio para a construção de indicadores de sustentabilidade energética reside na escolha de metodologias apropriadas que identifiquem, através da seleção e combinação de variáveis, os efeitos dos 51 investimentos em energia elétrica na dinâmica do desenvolvimento socioeconômico através dos meandros dos setores de uma economia (BORGES, 2009).

\section{EVOLUÇÃO NA ELABORAÇÃO DE INDICADORES ENERGÉTICOS DE SUSTENTABILIDADE}

O processo de elaboração de indicadores de sustentabilidade energética tomou aqui por recorte espacial o Estado do Pará e foi subsidiado nesta oportunidade a partir de uma metodologia de análise multivariada que procurou identificar variáveis com correlações lineares. $\mathrm{O}$ resultado de tal análise é um coeficiente que mensura o grau de dependência entre grandezas relacionadas, um valor que quantifica um nível de correlação denominado coeficiente de Pearson ( $p$ ) (BORGES, 20o9). Para que se possa começar a desenvolver o processo de construção dos indicadores de sustentabilidade energética se faz necessário relacionar a lista de variáveis e componentes observados que identificaram correlações lineares, de acordo com a natureza de suas dimensões: econômicas, sociais, ambientais e políticas; e a partir dos setores de atividade: agropecuário, industrial, comercial e residencial. São elas: consumo de energia elétrica; Produto Interno Bruto; unidade de consumo; valor 
investido em energia elétrica; tarifa média de energia elétrica; renda média do trabalhador; número de empregos gerados; coeficiente de Gini; rendimento energético; quantidade de emissões de dióxido de carbono $\left(\mathrm{CO}_{2}\right)$; quantidade de emissões de metano $\left(\mathrm{CH}_{4}\right)$; taxa de eletrificação dos domicílios; parcela de renda entre os 5\% mais ricos; e parcela de renda entre os 50\% mais pobres. A seguir, observa-se a estrutura para a construção de indicadores e índices de sustentabilidade energética (Quadros 5 e 6).

Quadro 5: Modelo para a construção de indicadores e índices de sustentabilidade energética nos setores econômicos.

\begin{tabular}{|c|c|c|}
\hline ÍNDICES & $\begin{array}{c}\text { INDICADOR } \\
\text { ES }\end{array}$ & COMPOSIÇÃO DAS VARIÁVEIS \\
\hline \multirow{3}{*}{$\begin{array}{c}\text { AGROPECUÁRI } \\
\text { O }\end{array}$} & Econômico & $\begin{array}{l}\text { - Relação entre o valor do Produto Interno Bruto no setor } \\
\text { agropecuário e a quantidade de Gwh consumida no setor. } \\
\text { - Relação entre o valor investido pela distribuidora } \\
\text { paraense em eletricidade no Estado e o valor do Produto } \\
\text { Interno Bruto, por unidade de consumo, no setor } \\
\text { agropecuário. } \\
\text { - Relação entre a tarifa média da eletricidade cobrada por } \\
\mathrm{kWh} \text { no setor agropecuário e o Produto Interno Bruto, } \\
\text { por unidade de consumo, neste setor. } \\
\text { Relação entre o valor investido pela distribuidora } \\
\text { paraense em eletricidade no Estado e o número de } \\
\text { unidades de consumo no setor agropecuário. }\end{array}$ \\
\hline & Social & $\begin{array}{l}\text { - Relação entre a quantidade de GWh consumida no setor } \\
\text { agropecuário e a renda média dos trabalhadores } \\
\text { paraenses. } \\
\text { - Relação entre a quantidade de GWh consumida no setor } \\
\text { agropecuário e o coeficiente de Gini registrado no Estado } \\
\text { do Pará. }\end{array}$ \\
\hline & Ambiental & $\begin{array}{l}\text { - Relação entre a quantidade de GWh consumida no setor } \\
\text { agropecuário e o rendimento energético verificado neste } \\
\text { setor. } \\
\text { - Relação entre a quantidade de GWh consumida no setor } \\
\text { agropecuário e a emissão acumulada gás metano }\left(\mathrm{CH}_{4}\right) \text { e } \\
\text { gás carbono }\left(\mathrm{CO}_{2}\right) \text { derivado de hidroelétricas no Pará. }\end{array}$ \\
\hline INDUSTRIAL & Econômico & $\begin{array}{l}\text { - Relação entre o valor do Produto Interno Bruto no setor } \\
\text { industrial e a quantidade de Gwh consumida no setor. } \\
\text { - Relação entre o valor do Produto Interno Bruto no setor } \\
\text { industrial e o número de unidades de consumo no setor. } \\
\text { - Relação entre a tarifa média da eletricidade cobrada por } \\
\text { kWh no setor industrial e o Produto Interno Bruto neste } \\
\text { setor. } \\
\text { - Relação entre o valor investido pela distribuidora } \\
\text { paraense em eletricidade no Estado e o número de } \\
\text { unidades de consumo no setor. }\end{array}$ \\
\hline
\end{tabular}




\begin{tabular}{|c|c|c|}
\hline & Social & $\begin{array}{l}\text { - Relação entre o valor investido pela distribuidora } \\
\text { paraense em eletricidade no Estado e o número de } \\
\text { empregos gerados no setor industrial. } \\
\text { - Relação entre a quantidade de } \mathrm{kW} \text { consumida no setor } \\
\text { industrial e o Coeficiente de Gini registrado no Pará. } \\
\text { Relação o número de unidades de consumo no setor } \\
\text { industrial e o Coeficiente de Gini registrado no Pará. }\end{array}$ \\
\hline & Ambiental & $\begin{array}{l}\text { - Relação entre a quantidade de } \mathrm{GWh} \text { consumida no setor } \\
\text { industrial e o rendimento energético verificado neste } \\
\text { setor. } \\
\text { - Relação entre a quantidade de } \mathrm{GWh} \text { consumida no setor } \\
\text { industrial e a emissão acumulada gás metano }\left(\mathrm{CO}_{2}\right) \text { e gás } \\
\text { carbono }\left(\mathrm{CO}_{2}\right) \text { derivado de hidroelétricas no estado do } \\
\text { Pará. }\end{array}$ \\
\hline \multirow[t]{3}{*}{ COMERCIAL } & Econômico & $\begin{array}{l}\text { - Relação entre o valor do Produto Interno Bruto no setor } \\
\text { - } \\
\text { Relação entre o valor do Produto Interno Bruto no setor } \\
\text { comercial e o número de unidades de consumidoras no } \\
\text { setor. } \\
\text { Relação entre o valor investido pela distribuidora } \\
\text { paraense em eletricidade no Estado e o número de } \\
\text { unidades de consumidoras no setor comercial. } \\
\text { Relação entre o valor investido pela distribuidora } \\
\text { paraense em eletricidade no Estado e a quantidade de } \\
\text { Gwh consumida no setor comercial. } \\
\text { Relação entre a quantidade de GWh consumida no setor } \\
\text { comercial e a tarifa média da eletricidade cobrada por } \\
\text { kWh no setor. } \\
\text { Relação entre a quantidade de GWh consumida no setor } \\
\text { comercial e o número de unidades de consumidoras no } \\
\text { setor. } \\
\text { Relação entre a tarifa média da eletricidade cobrada por } \\
\text { kWh no setor comercial e o número de unidades de } \\
\text { consumidoras no setor. }\end{array}$ \\
\hline & Social & $\begin{array}{l}\text { - Relação entre a quantidade de GWh consumida no setor } \\
\text { comercial e o número de empregos gerados neste setor. } \\
\text { Relação entre o número de unidades de consumidoras no } \\
\text { setor comercial e o número de empregos gerados neste } \\
\text { setor. } \\
\text { - Relação entre o valor investido pela distribuidora } \\
\text { paraense em eletricidade no Estado e o número de } \\
\text { empregos gerados no setor comercial. } \\
\text { - Relação entre a quantidade de KW consumida no setor } \\
\text { comercial e o coeficiente de Gini registrado no Estado do } \\
\text { Pará. }\end{array}$ \\
\hline & Ambiental & $\begin{array}{l}\text { - Relação entre a quantidade de GWh consumida no setor } \\
\text { comercial e o rendimento energético verificado neste } \\
\text { setor. } \\
\text { - Relação entre a quantidade de GWh consumida no setor } \\
\text { comercial e a emissão acumulada gás metano }\left(\mathrm{CH}_{4}\right) \\
\text { derivado de hidroelétricas no Estado do Pará. }\end{array}$ \\
\hline
\end{tabular}




\begin{tabular}{|l|l|l|}
\hline & $\bullet \quad \begin{array}{l}\text { Relação entre a quantidade de GWh consumida no setor } \\
\text { comercial e a emissão acumulada de gás dióxido de } \\
\text { carbono }\left(\mathrm{CO}_{2}\right) \text { derivado de hidroelétricas no Estado do } \\
\text { Pará. }\end{array}$ \\
\hline
\end{tabular}

Fonte: Elaborado pelo autor (2020).

A seguir, observa-se o modelo para a construção de indicadores e índices de sustentabilidade energética no setor residencial (Quadro 6).

Quadro 6: Modelo para a construção de indicadores e índices de sustentabilidade energética no setor residencial.

\begin{tabular}{|c|c|c|}
\hline & Econômico & $\begin{array}{l}\text { - Relação entre o valor investido pela distribuidora paraense } \\
\text { em eletricidade no Estado e a quantidade de } \mathrm{kW} \\
\text { consumida no setor residencial. } \\
\text { - Relação entre o valor investido pela distribuidora paraense } \\
\text { em eletricidade no Estado do Pará e o valor da tarifa média } \\
\text { da eletricidade cobrada por } \mathrm{kWh} \text { no setor residencial. } \\
\text { - Relação entre o número de unidades consumidoras e a } \\
\text { tarifa média da eletricidade cobrada por kWh no setor. } \\
\text { - Relação entre a quantidade de GWh consumida no setor } \\
\text { residencial, por unidade de consumo, e a tarifa média da } \\
\text { eletricidade cobrada por } \mathrm{kWh} \text { no setor. }\end{array}$ \\
\hline RESIDENCIAL & Social & $\begin{array}{l}\text { - Relação entre a taxa de eletrificação do Estado e a parcela } \\
\text { da renda dente os } 50 \% \text { mais pobres no Pará } \\
\text { Relação entre a tarifa cobrada no setor residencial e a taxa } \\
\text { de eletrificação do Estado do Pará. } \\
\text { - Relação entre o valor investido pela distribuidora paraense } \\
\text { em eletricidade no Estado do Pará e a taxa de atendimento } \\
\text { público de energia elétrica em domicílio. } \\
\text { - Relação entre o consumo de energia elétrica no setor } \\
\text { residencial e o coeficiente de Gini no Pará. } \\
\text { Relação entre o valor investido pela distribuidora paraense } \\
\text { em eletricidade no Estado do Pará e o percentual de renda } \\
\text { dos 5\% mais ricos da população paraense } \\
\text { Relação entre a tarifa cobrada no setor residencial e o } \\
\text { coeficiente de Gini no Pará. } \\
\text { 3Relação entre o consumo de energia elétrica no setor } \\
\text { residencial e a taxa de eletrificação no Pará. } \\
\text { Relação entre o coeficiente de Gini no Estado do Pará e a } \\
\text { taxa de eletrificação no Estado do Pará. } \\
\text { Relação entre a quantidade de energia elétrica exportada } \\
\text { pelo Estado do Pará e a parcela de renda dos 5\% mais ricos } \\
\text { da população paraense } \\
\text { - Relação entre a tarifa cobrada no setor residencial e a } \\
\text { parcela de renda dos } 5 \% \text { mais ricos da população paraense } \\
\text { Relação entre a tarifa cobrada no setor residencial e a } \\
\text { parcela da renda dente os 5o\% mais pobres no Pará. } \\
\text { Relação entre a quantidade de energia elétrica exportada } \\
\text { pelo Estado do Pará e o percentual de renda dos } 50 \% \text { mais } \\
\text { pobres da população paraense }\end{array}$ \\
\hline
\end{tabular}




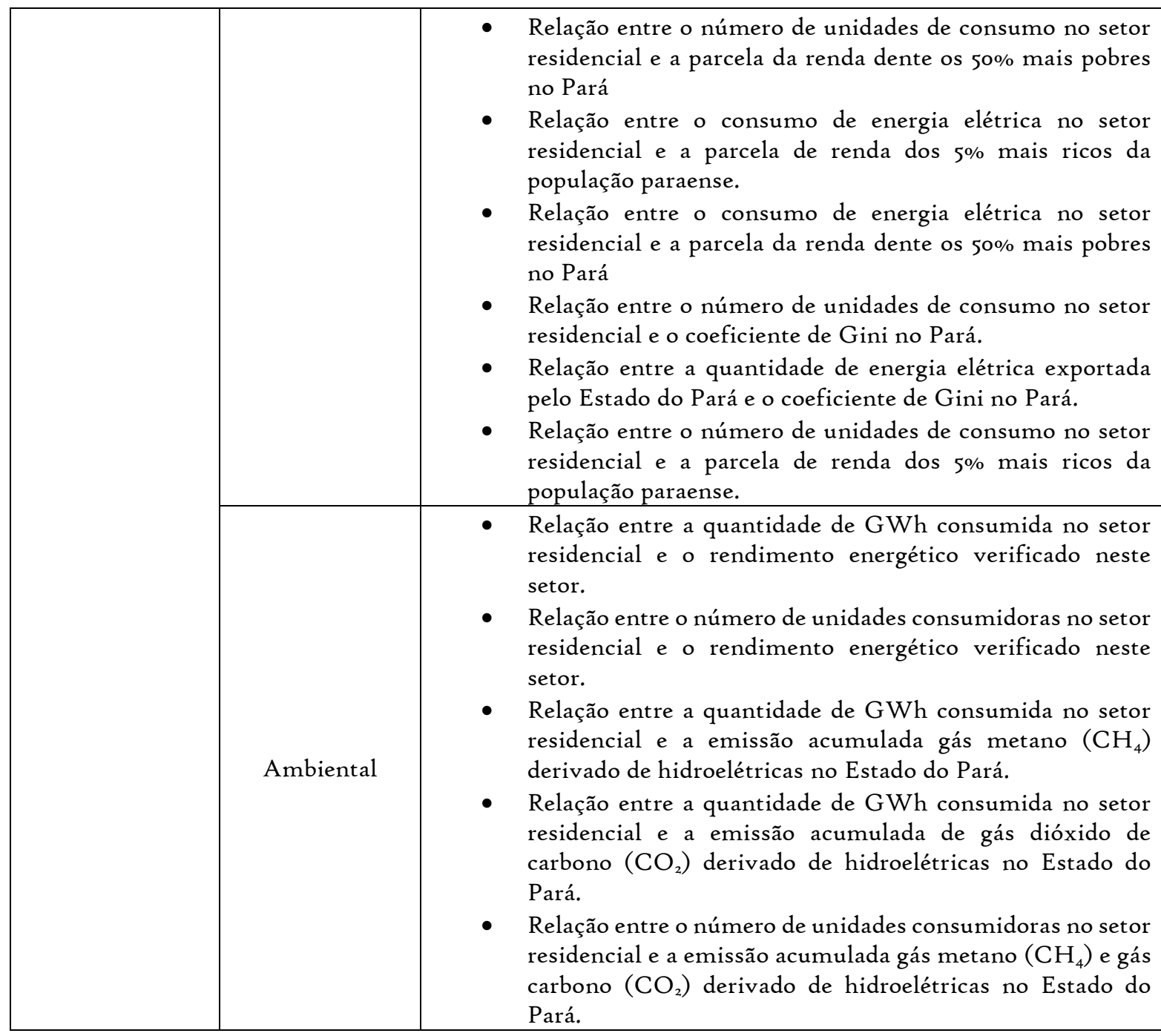

Fonte: Elaborado pelo autor (2020).

O índice de sustentabilidade energética de cada setor baseou-se na agregação dos indicadores: econômico, social e ambiental.

\section{${ }_{4}$ CONSIDERAÇÕES FINAIS}

Esta investigação concluiu, em cômputo geral, que a elaboração de indicadores de sustentabilidade de energia elétrica obteve um resultado bastante satisfatório quando da utilização da análise multivariada. Destaca-se que foram identificadas variáveis com correlações lineares de acordo com a natureza de suas dimensões: econômicas, sociais, ambientais e políticas; e a partir dos setores de atividade no Estado paraense. 
Observou-se que a discussão apresenta uma alternativa metodológica interessantes de indicadores de sustentabilidade para a energia elétrica que identifica dinâmicas nos aspectos econômico, social e ambiental. Somente a partir desta compreensão será possível orientar um processo de tomada de decisão dentro do setor elétrico do estado paraense. Esta lógica também se aplica a outros estados e/ou regiões que pretendem melhor posicionar suas decisões utilizando a energia como vetor estratégico no processo de desenvolvimento.

\section{REFERÊNCIAS}

AGÊNCIA NACIONAL DE ENERGIA ELÉTRICA. Proposta de indicadores de sustentabilidade energética da ANEEL. Brasília: Aneel, 1999.

BERMANN, C. Energia no Brasil, Para que? Para quem?: crise e alternativa para um país sustentável. São Paulo: Editora Livraria da Física, 2002.

BRUYN, S., \& DRUNDEN, M. Sustentability and indicators in Amazon: conceptual framework for use in Amazon. Amsterdam: Vrije, 1999.

BORGES, F. Q. Indicadores de Sustentabilidade para a Energia Elétrica no Estado do Pará. Revista Brasileira de Energia. v. I5 n. 2, 2009.

CAMARGO, A. S. G., UGAYA, C. M. L., \& AGUDElO, L. P. P. Proposta de definição de indicadores de sustentabilidade para geração de energia elétrica. Revista Educação \& Tecnologia, (8), 2004 .

FISCHER-KOWALSKI, M., HABERL, H., HÜTTLER, W., PAYER, H., SCHANDL, H., WINIWARTER, V., ZANGERL-WEISZ, H. Gesellschaftlicher stoffwechsel und kolonisierung von natur. Amsterdam: Verlag Fakultas, 1997.

HELIO INTERNATIONAL Guidelines for observe: reporters. Recuperado de: http://www.heliointernational.org.. s/d. s/e, 2005

INSTITUTO BRASILEIRO DE GEOGRAFIA E ESTATÍSTICA. Mapas interativos. Rio de Janeiro, 2005.

KALTENEGGER, C. Der Reformproze in der VR China: aktueller stand der wirtschaftsreformen und aussichten. CA Quarterly I, I995.

KITAMURA. C. P. A Amazônia e o desenvolvimento sustentável. Brasília: EMBRAPA, 1994.

ORGANIZAÇÃO LATINO-AMERICANA DE ENERGIA. Sistemas de informaciones energéticas e económicas. Quito: SIEE, 1996.

REIS, L. B., FADIGAS, E. A. A., \& CARVALHO, C. E Energia, recursos naturais e a prática do desenvolvimento sustentável. Barueri-SP: Manole, 2012. 
SMIL, V. China's Environmental Crisis: An Enquiry into the Limits of National Development: An Enquiry into the Limits of National Development. New York: East Gate, 1993.

SPANGENBERG, J. Measuring and communicating sustainability with indicators: terms of reference for a CSD core indicator test in main catchment area regions. New York: UN/E/CN, 2000.

SUAREZ, C. E. Energy needs for sustainable human development. In: Goldemberg, J. E., \& Johansson, T. B. (Org.) Energy as an instrument for socioeconomic development. New York, UNDP, 1995 . 